\title{
A discussion on the order of magnitude of corrosion current density in reinforcements of concrete structures and its link with cross-section loss of reinforcement
}

\author{
Raoul François ${ }^{1,2 *}$ \\ ${ }^{1}$ LMDC, INSA, UPS, Université de Toulouse, France \\ ${ }^{2}$ Corrohm, France
}

Received: 25 June 2021 / Accepted: 30 January 2022 / Published online: 28 February 2022

(C) The Author(s) 2022. This article is published with open access and licensed under a Creative Commons Attribution 4.0 International License.

\begin{abstract}
This paper deals with the determination of the corrosion current density in chloride-induced corrosion in reinforced concrete structures. Because the corrosion of steel bars is generally localized, calculations of the densities of corrosion current need to take the real surface areas of anodic zones into account. Nowadays, in the lab or on site, the calculation of densities of corrosion are based on arbitrary steel surface areas, which merge anodic and cathodic zones. As a result, the order of magnitude of corrosion current density is not correct; it is underestimated. A second aspect of the paper is the relationship between corrosion current density and the prediction of service life in RC structure when including a part of the propagation phase. The consequences of the corrosion current density on mechanical properties such as corrosion-induced cracking or load-bearing capacity must consider that anodic areas grow both laterally and in-depth.
\end{abstract}

Keywords: Corrosion current density; Reinforced concrete; Anodic current density; Chlorides; Corrosion pit growth

\section{Introduction}

The problem of corrosion of concrete reinforcement is a very important one, recently recalled and analyzed in its many aspects by Angst [1]. A crucial parameter among all those involved is the value of the corrosion current density.

Nowadays, New or future standards (such as FIB Model Code 2020) concerning the requalification of existing structures exposed to corrosion are being drawn up to predict their remaining service life. In the same way, prediction of service life of new structures will be including a part of the propagation phase. Criteria for the end of service life are then proposed, such as the appearance of the first corrosioninduced crack, and some proposed models use the corrosion rate, which is based on values established during the work of the RILEM TC 154 EMC committee [2] and then calculated using the total surface area of the steel bars.

The criterion of end of service life corresponding to the appearance of the first visual damage (first corrosion -induced cracks) is a relevant criterion since it corresponds to a change in the corrosion process. As the beginning of the propagation phase, chloride-induced corrosion is localized with small anode areas which exchange current with large cathode areas: it corresponds then to macrocell corrosion. In this paper, the macrocell corrosion corresponds to the situation where active dissolution (oxidation of iron) and the corresponding cathodic reaction (reduction of oxygen) do no take place at the same location: it corresponds then to the presence of a corrosion spot. The $\mathrm{pH}$ of cementitious materials is fundamentally very high, and each corroding spot is surrounded by large cathodic areas, where oxygen is reduced and significant amounts of $\mathrm{OH}$ - (hydroxide) ions are generated and attracted to the adjacent anodic zone by the macrocell electric field, thus impeding large $\mathrm{pH}$ decrease. As a result, this macro-cell process leads to more lateral growth of anodic spots, than in-depth penetration [3]. The author of this paper has studied and monitored the development of chloride-induced corrosion of different set of reinforced concrete beams exposed to salt fog spraying during 28 years. A statistical analysis, not yet published, allow to show that there is a clear change in the in-depth penetration in pitting zones, before and after appearance of corrosion-induced cracks. One explanation is probably, that after the appearance of corrosion-induced cracks, anodic zones in front of cracks move gradually to a mix between macrocell and microcell corrosion. In microcell corrosion process facing to corrosion-induced cracks, an acidification may take place inside the pit [4] increasing the in-depth penetration process.

\footnotetext{
* Corresponding author: Raoul François, E-mail: raoul.francois@insa-toulouse.fr
} 
Traditionally, when we speak of corrosion current density, we refer to the values resulting from the work of the RILEM TC 154 EMC committee, with values of corrosion current densities said to be significant or important from $1 \mu \mathrm{A} / \mathrm{cm}^{2}$ [2]. These values are identical to those identified by Broomfield et al. [5].

Table 1. Ranges of corrosion and penetration rates with the corresponding corrosion levels [2].

\begin{tabular}{|l|l|l|}
\hline $\begin{array}{l}\mathrm{I}_{\text {corr }} \\
{\left[\mu \mathrm{A} / \mathrm{cm}^{2}\right]}\end{array}$ & $\begin{array}{l}\mathbf{V}_{\text {corr }} \\
{[\mathrm{mm} / \text { year }]}\end{array}$ & Corrosion level \\
\hline$\leq 0.1$ & $\leq 0.001$ & Negligible \\
\hline $0.1-0.5$ & $0.001-0.005$ & Low \\
\hline $0.5-1$ & $0.005-0.010$ & Moderate \\
\hline$>1$ & $>0.010$ & High \\
\hline
\end{tabular}

These corrosion current density values are still used as an order of magnitude to characterize corrosion in the propagation phase. As a result, most models that can be found in the literature for the propagation phase lead to current densities of the order of $1 \mu \mathrm{A} / \mathrm{cm}^{2}$ to $2 \mu \mathrm{A} / \mathrm{cm}^{2}$ [69].

Corrosion current densities from Table 1 are used to calculate a uniform reduction of reinforcing bar cross-section and, if the density is assumed to be constant over 1 year, this corresponds to a reduction in the reinforcement radius of about $0.01 \mathrm{~mm}$ / year. For a reinforcement with a diameter of $16 \mathrm{~mm}$, this corresponds to a loss of cross-section of $0.3 \%$ / year, which makes it possible to guarantee the mechanical stability for decades [10] (taking the load bearing capacity into account), and could justify the use of this value a posteriori.

The authors of the TC RILEM 154 EMC report [2] were aware of the existence of a galvanic corrosion process (or macrocell corrosion process) at least coexisting with that of uniform corrosion, but they decided that the uniform corrosion current density was greater than that of galvanic current.

Moreover, as explicitly pointed out by Andrade [10], a large proportion of the community working in the field of corrosion of reinforcements in concrete continues to consider that the corrosion process is mainly uniform or micro-cell corrosion, which justifies the concept of $I_{\text {corr }}$ defined by the RILEM TC 154-EMC committee [2].

There are some models, analytical $[11,12]$ or numerical $[9,13-$ $15]$, that take account of the existence of a galvanic process by adding a cathode to anode ratio into the calculation of the corrosion current density. However, the main problem lies in defining the size of the anodic area.

To take the localized aspect of corrosion into account, the authors involved in the work of the RILEM TC 154 EMC [16,17] defined a pitting corrosion current density (Eq. 1) with a multiplying coefficient of the corrosion current density: $\alpha_{\text {pit, }}$

$$
\mathrm{I}_{\text {pit }}=\alpha_{\text {pit }} \mathrm{I}_{\text {corr }}\left[\mathrm{A} / \mathrm{cm}^{2}\right]
$$

with $\alpha_{\text {pit }}$ varying between 3 and 10. A high corrosion current density for pit growth is therefore $10 \mu \mathrm{A} / \mathrm{cm}^{2}$.

Elsener [18] also points out that local penetration rate can be up to 5 or 10 times the calculated corrosion rate.
Many authors have also used the concept of pitting factor to predict the difference between the loss of cross-section in general corrosion and the maximum pit depth, especially for chloride-induced corrosion [19-24]. They find a ratio between maximum and average corrosion ranging between 2.4 and 16.1. Because local loss of cross-section is not necessarily related to the pit depth, Harnisch and Raupach [25] introduce a residual cross section factor. Nevertheless, pitting factor measurement could only be destructive and would frequently correspond to measurements made after the appearance of corrosion-induced cracks. In this case, the corrosion process is different from that occurring before the appearance of corrosion-induced cracks. Secondly, the location of most severe pitting is likely to change with time [26] and then the pitting factor is not related to the difference between the anodic corrosion current and the average corrosion current. Finally the calculation of the average loss of cross-section is also questionable since it merges corroded zones with noncorroded zones.

The diagnosis of corrosion of concrete structures is mainly based on visual inspection and mapping of steel/concrete potential measurements but it does not lead to information on the corrosion kinetics. To obtain some information about corrosion rate, on-site measurements are based on indirect measurements of corrosion current density using commercial devices based on an anodic and cathodic polarization of the reinforcements via the Linear Polarization Resistance technique (LPR). The results are then interpreted in terms of polarization resistance (Rp), which is transformed into corrosion current density using the Stern-Geary formula [27]. The corresponding values are then interpreted according to the densities resulting from the work of TC RILEM 154-EMC to define the corrosion state of the structure [2].

It is now well recognized and understood that indirect measurements of the corrosion current are subject to multiple errors in the case of corrosion of reinforcements in concrete [28-32]. The corrosion type is "non-uniform" or "localized" or "galvanic", which corresponds to the presence of spatially separated anodic and cathodic zones. In this configuration, there are 3 major errors in the indirect measurement of the corrosion current: $1 /$ the assumption of identical polarization of the anodic and cathodic zones, $2 /$ the assumption of the surface area of polarized steel, which would be related to the geometry of the measuring device, 3 / the interpretation of the apparent measurement of Rp based on the Stern-Geary equation, which is invalid for "localized" corrosion. This observation does not negate the very real possibility that the measurement of the "apparent" polarization resistance $\mathrm{Rp}$ could be related to the corrosion current density; this point was highlighted by Angst and Büchler [29] and Laurens [33]. To date, however, the interpretation of "apparent" Rp is not able to give a corrosion current density.

It should be mentioned that many authors [2,10,12,34-38] have found LPR based corrosion rates to correspond to mass loss measurements. Mass loss measurements give obviously a relevant information of corrosion losses, but in localized corrosion process such as chloride-induced corrosion, the 
corroded zones do not correspond to the entire surface of the re-bar which is weighed. As a result, the corrosion rate calculated from mass loss merge non-corroded area and corroded area and is then not representative of the corrosion current density.

To be able to predict the service life of existing or new structures, it is necessary to have reliable values of corrosion current density. This would allow the actual local reduction in cross-section to be calculated, which is the key parameter for re-evaluation of corroded reinforced concrete structures [25]. To establish such values of corrosion current density, it is necessary to recall the phenomenological aspect of corrosion in reinforced concrete structure.

It is also necessary to recall that $i_{\text {corr }}$ is the loss of electrons occurring at the anodic site, per unit of steel surface, of the corrosion cell and is measured in microamps per square centimeter: without knowledge of the size of the anodic site, the calculation of $\mathrm{i}_{\text {corr }}$ is erroneous. It is similar to the situation of a structural engineer calculating the tensile stress in the reinforcement of a concrete beam without knowing the cross-section of steel reinforcement.

The first part of this paper will be dedicated to the calculation of the corrosion current density by using experimental results from Chalhoub et al. [39], where the anodic surface was calculated.

The second part will highlight the effect of resistivity on the corrosion current density, due to the mitigation of exchanges between anodic and cathodic zones.

The third part will recall that corrosion engineers must be aware that corrosion current density may be used by structural engineers and so there is a need for a clear definition distinguishing between corrosion current density and loss of steel cross-section.

\section{Corrosion process in reinforced concrete structure}

The chloride-induced corrosion in reinforced concrete structures is localized (Figure 1). It corresponds to a separation between anodic and cathodic areas, and then could be also qualified as "galvanic corrosion". In RC structures, at the beginning of the corrosion process, a high ratio between cathodic and anodic areas exists. Indeed, RC structures have several longitudinal (or main) reinforcement layers that are intended to take up tensile stresses (for tie rods and bent elements) or to ensure non-brittleness for compressed elements. Main reinforcements are in electrical continuity by means of the transverse reinforcements (stirrups) which have the object of bearing shear forces or simply allowing the positioning of the longitudinal reinforcements in the formwork. Most part of the reinforcement is still passive (Figure 1 ) because not contaminated by chloride ingress at the beginning of the corrosion process.

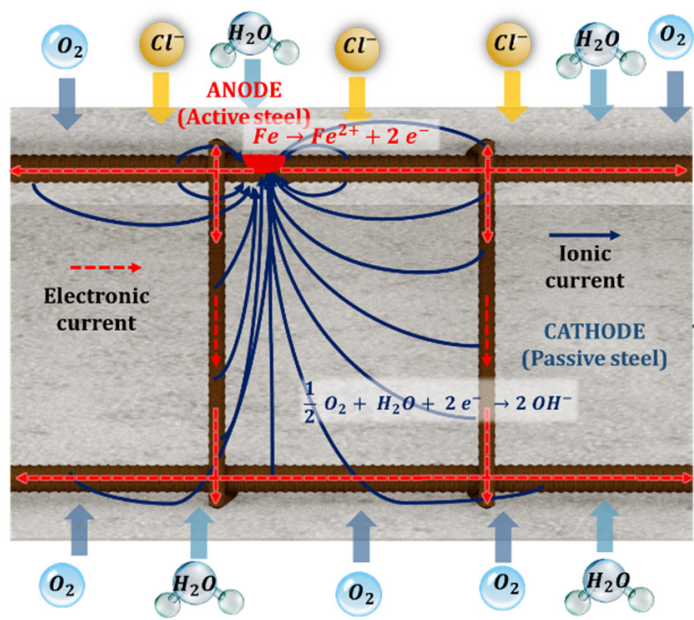

Figure 1. Localized corrosion due to chlorides.

In the case of "galvanic" corrosion, it is possible to measure a corrosion current between the anode and the cathode "directly", via an ammeter, or a potentiostat in ZRA mode, or by measuring the potential difference at the ends of a calibrated resistance connecting anode and cathode, provided that the anodic and cathodic zones are clearly identified and defined.

This is the case in the experimental protocol developed by Chalhoub et al. [39], which physically separates the anode and cathode to measure the corrosion current flowing between them (Figure 2). Based on the comparison between mass loss measurement and macrocell corrosion rates, it was concluded that residual microcell rates were negligible in comparison with the macrocell rate itself. Such results are also found in $[40,41]$.

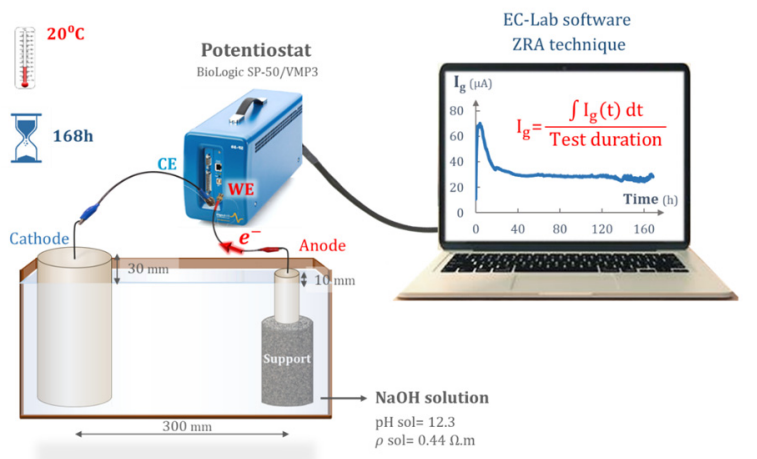

Figure 2. Cathode-anode coupling and measurement of the galvanic current (from [39])

Localized corrosion process which occurs in reinforced concrete, with separation of the anodic zone and the cathodic zone, leads to a relationship between the corrosion current density and the resistivity of the concrete. This relationship will, of course, depend on the geometry of the structure studied. However, to fix orders of magnitude, the relationship between corrosion current density and resistivity will be given for the geometry of the experimental protocol developed by Chalhoub et al. [39]. 
Because it is very difficult to find corrosion current density that takes the real anodic surface area into account in the literature, this paper gives an order of magnitude of corrosion current density using the results obtained by Chalhoub et al. [39]

The protocol used by Chalhoub et al. [39] is suitable to describe the on-site chloride-induced corrosion process. Firstly, on RC structures, at the beginning of the propagation phase of corrosion, there is a high Cathode/Anode ratio (C/A) due to the fact that the deeper layers of reinforcing bars play the role of cathode. Secondly, on RC structures, the macrocell process involved in chloride-induced corrosion, lead to increase the chloride content at anodic area due to the electro-migration of chlorides [42]. Thirdly, on RC structures, the chloride-induced corrosion occurs for high saturation degree because of the hygroscopic properties of sodiumchloride solution, which lead to reduce the vapor pressure saturation [43] in pores.

Finally, the short duration of the experiments (only 7 days) do not appear to be a limitation since others experiments in process at LMDC [44] show the same order of magnitude for corrosion current density after one year.

The main limitation of the paper is the case of permanently submerged RC structures with a possible lack of oxygen for cathodic reaction which is not taken into account in this paper.

\section{Experimental protocol used to measure corrosion current densities}

The experimental protocol developed by Chalhoub et al. [39] consists of an anode containing a ribbed steel bar $1 \mathrm{~cm}$ long and $6 \mathrm{~mm}$ diameter, which will be called the apparent anode and which can be polluted by chlorides, and a cathode of variable dimension that remains in the passive state. The typical value of the cathode / apparent anode ratio chosen by Chalhoub et al. [39] is 16 (Figure 2).

In the case of corrosion induced by chlorides, the apparent anode, despite its small size, is not entirely active: it also comprises anodic areas and cathodic areas. This confirms the intrinsically localized aspect of corrosion induced by chlorides with small local depassivation zones. The actual size of the anodic areas can only be determined from X-Ray tomographic analysis or by destroying the sample.

This article summarizes the results obtained with a standard mortar (M1) based on CEM I (composition shown in Table 2) and published by Chalhoub et al. [39].
Table 2. Mortar formulation.

\begin{tabular}{|l|l|}
\hline \multicolumn{2}{|l|}{ CEM I Mortar mixture } \\
\hline Materials & Quantity $\left(\mathrm{kg} / \mathrm{m}^{3}\right)$ \\
\hline Siliceous sand 0/4 & 1408 \\
\hline CEMI 52.5 R (Lafarge company) & 512 \\
\hline Water & 281.4 \\
\hline Water/Cement & 0.55 \\
\hline
\end{tabular}

\section{Corrosion current densities for corrosion} induced by chlorides

\subsection{Corrosion current density (calculated from the anodic surface)}

For the standard M1 mortar, Chalhoub et al. [45] studied the evolution of the galvanic corrosion current, $\mathrm{l}_{\mathrm{g}}$, between the apparent anode, contaminated by different levels of chlorides, and the cathodes.

The protocol for contamination by chlorides carried out by imbibition can be found in Chalhoub et al. [39].

Beyond the chloride threshold initiating corrosion, the galvanic current $\mathrm{I}$ increases with chloride concentration, the relationship between the free chloride content and the apparent current density (calculated versus the total surface of the apparent anode) being quasi linear (Figure 3).

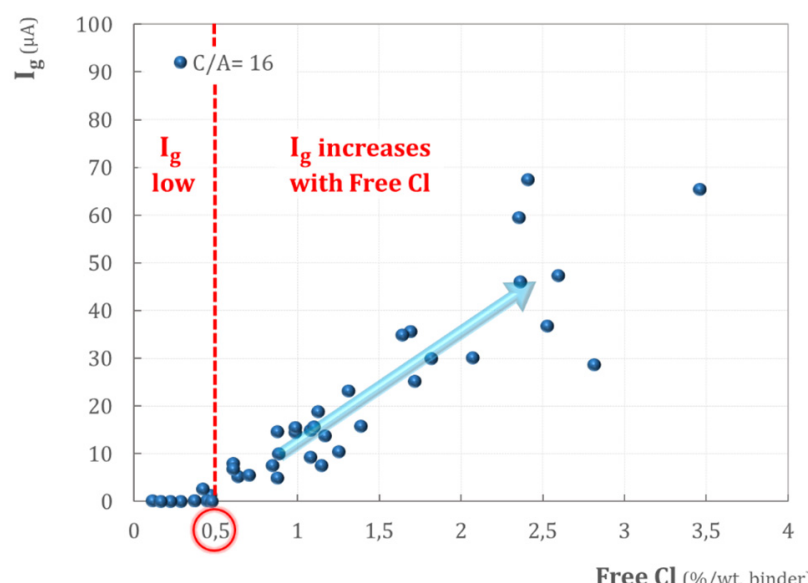

Figure 3. Galvanic current $\mathrm{I}_{\mathrm{g}}$ between the apparent anode and the cathode as a function of the concentration of free chlorides at the anode.

The galvanic current $\mathrm{I}_{\mathrm{g}}$ was expressed in terms of apparent corrosion current density by Chalhoub et al. [45] because this value is easy to calculate at the end of the test. To determine the corrosion current density, it is necessary to know the actual anodic surface area of the apparent anode.

As shown in Figure 4, only part of the apparent anode is actually corroded, and this really anodic surface of the apparent anode depends on the level of free chlorides. Chalhoub et al. [45] measured the actual corroded area of different apparent anodes, and then calculated the corrosion current density. The calculation of the size of anodic zones is performed by image analysis by comparing the $\mathrm{X}$-ray microtomography at a given time with the initial one without any corrosion. 

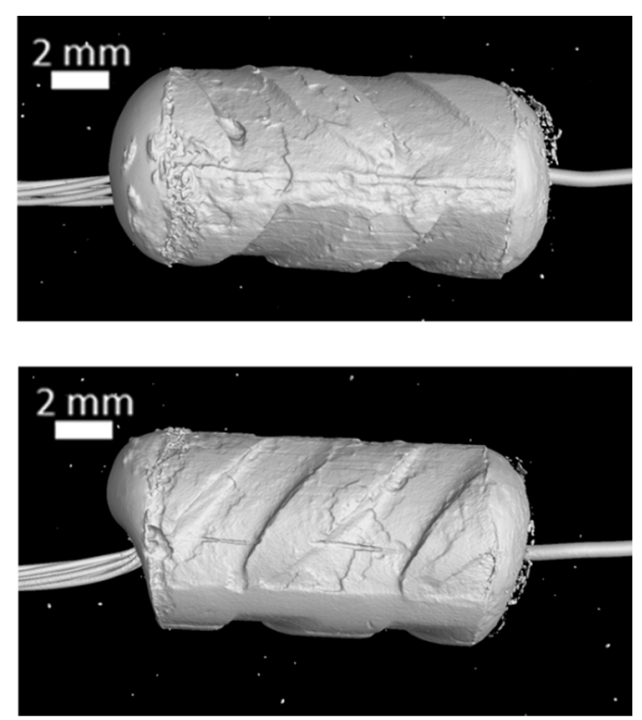

Figure 4. The sample (shown from different angles) is contaminated with a free $\mathrm{Cl}$ content of 2.07 \%/wt. binder (X-ray Tomography (CEA Saclay, France)) (from [45]).
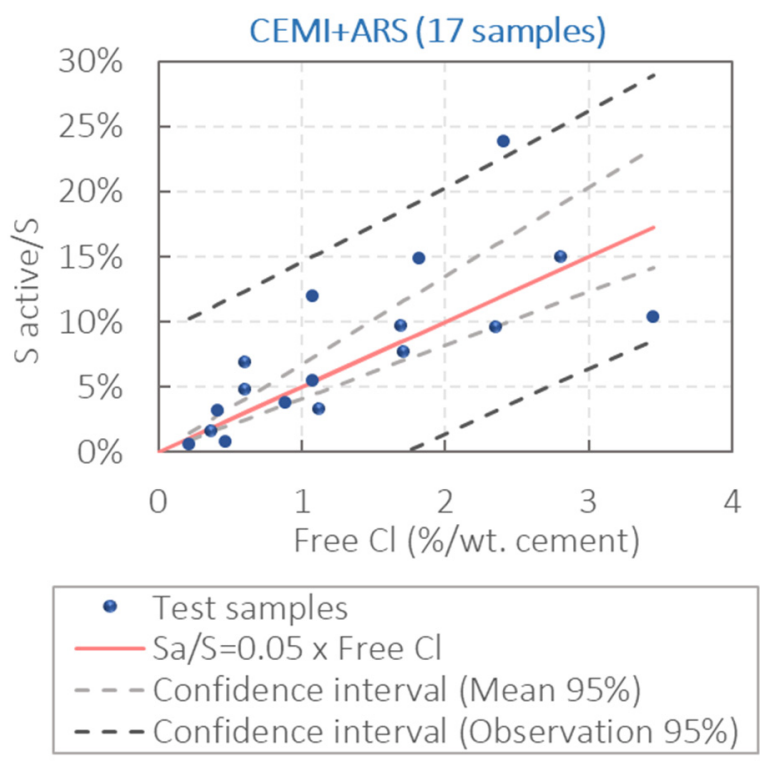

Figure 5. Evolution of the actual anodic surface on an apparent anode as a function of the content of free chlorides.

From the measurement of the real corroded surface area of the apparent anode (Figure 5), we can calculate the corrosion current density $i_{\text {corr }}$, by dividing $I_{g}$ per the anodic surface, as a function of the amount of free chlorides present near the reinforcement in the porosity of the concrete (Figure 7).

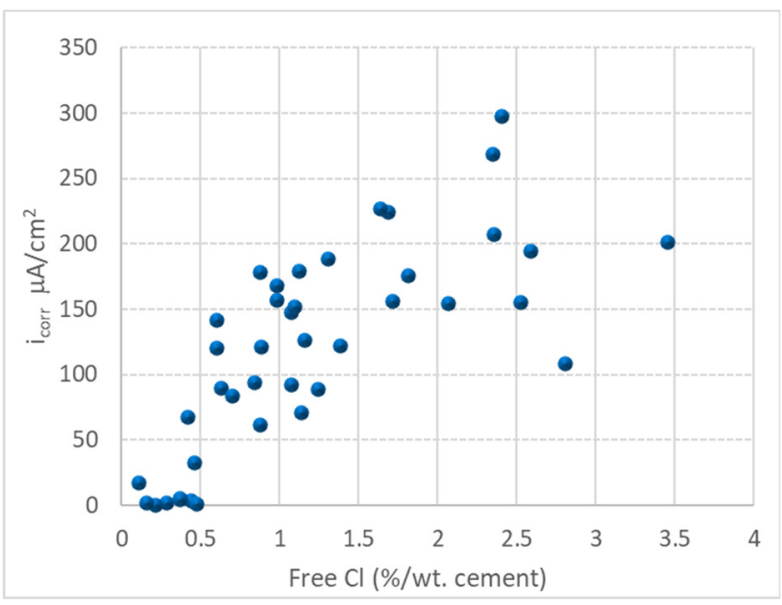

Figure 7. Evolution of the corrosion current density icorr according to the free chloride content.

The corrosion current density varies between $50 \mu \mathrm{A} / \mathrm{cm}^{2}$, immediately above the chloride threshold, up to values of 150 to $300 \mu \mathrm{A} / \mathrm{cm}^{2}$ for free chloride contents above $2 \%$ by mass of cement. The corrosion current density for ordinary concrete is therefore greater than $50 \mu \mathrm{A} / \mathrm{cm}^{2}$ as soon as corrosion becomes active beyond the threshold for depassivation by chlorides. It is therefore clear that the conventional value of corrosion current density (Table 1) indicating significant corrosion $\left(1 \mu \mathrm{A} / \mathrm{cm}^{2}\right)$ is largely underestimated.

However, the corrosion current density value will depend on the resistivity of the concrete and this point will be the subject of the next section.

The corrosion current densities shown Figure 7, far-away from the conventional values (Table 1), may seem shocking if it is transformed into a loss of section of reinforcements on the basis of the usual assumption, which is that the total corrosion current leads to a reduction of the cross-section. In reality this is not the case: Figure 10 recalls the "localized" corrosion mechanism of the reinforcements, which leads to maximum activity on the edges of the anodic area. As a result, the anode areas extend in length rather than in depth (Figure 11) [3].

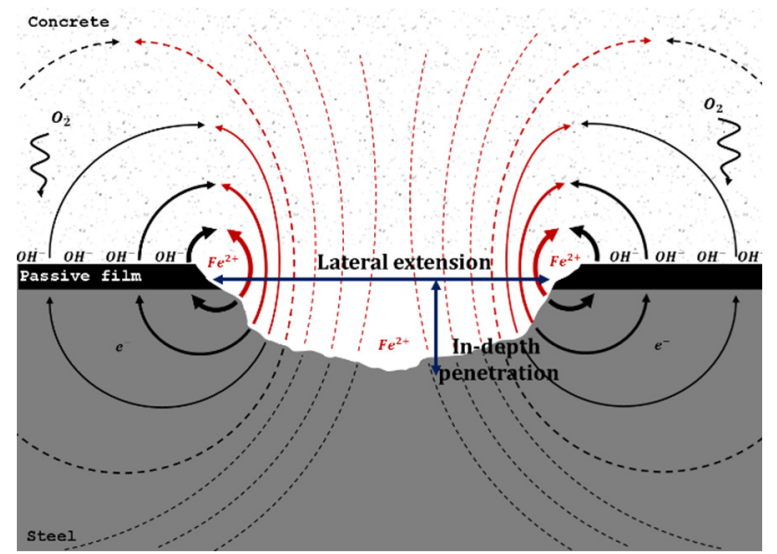

Figure 9. Localized corrosion mechanism : extension in length of anodic zone due to higher current density at the border between anodic and cathodic zones: adapted from [3]. 


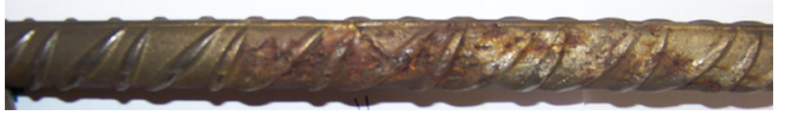

Figure 10. Localized corrosion mechanism: on site evidence on reinforced steel bar.

Therefore, the corrosion current density cannot be unequivocally linked with the loss of reinforcement crosssection. Probably, but this remains an open question, the fraction of the corrosion current density leading to the reduction in the reinforcement cross-section is very small compared to that corresponding to the extension of the anode areas. This is also highlighted in [25] by Harnisch and Raupach, who explain that the reduction of pitting factor with time could be due to more lateral corrosion damage at corrosion spots. Results from Robuschi et al. [46] also support the laterally extension of anodic area.

Different authors [14, 47,48] used experiments based on macro-cell corrosion process: they measured apparent "galvanic" corrosion currents that were of the same order of magnitude as those of Chalhoub et al. [39-45]. Jaggi et al. [47] measured macro-cell corrosion currents between separate anodes and cathodes and found values of the order of magnitude of 10 to $20 \mu \mathrm{A} / \mathrm{cm}^{2}$ but, in their study the surface of the anode actually corroded is unknown. Warkus and Raupach [14] measured macro-cell corrosion currents between anodes and separate cathodes and found values of the order of 3 to $4 \mu \mathrm{A} / \mathrm{cm}^{2}$ but, here again, the surface of the anode actually corroded was unknown. Yalçyn and Ergun [48] measured densities of corrosion currents in concrete polluted by chlorides (1.7\% of $\mathrm{Cl}^{-}$added during casting) and found 2.2 $\mu \mathrm{A} / \mathrm{cm}^{2}$ at 28 days.

Bolzoni et al. [19] and Ormellese et al. [49] made some measurements of the maximum depth of localized corrosion in comparison with both average mass loss and the LPR method to evaluate corrosion rate. They found a localized penetration rate in the range of $350-400 \mu \mathrm{m} /$ year corresponding to a range of 8-10 $\mu \mathrm{m} /$ year for average mass loss, and 15-24 $\mu \mathrm{m} /$ year for LPR. The ratio between mean value and maximum penetration rate was then about 40 .

\subsection{Corrosion current density based on the total surface area of steel (merging anodic and cathodic parts)}

In the case of uniform corrosion, the corrosion current density is calculated according to the total area of the steel bar. In the case of localized corrosion, calculating the corrosion current density according to the total area of the steel bar leads to a conventional corrosion current density (Table 1) since the total area of the steel bar corresponds to the sum of cathode and anode areas.

Figure 12 shows the conventional corrosion current density $\mathrm{i}_{\text {corr (c) }}$ calculated from the total surface of steel bars and corresponding to the galvanic currents presented in Figure 3. From Figure 12, it can be seen that above the chloride threshold for corrosion initiation in the apparent anode, the conventional corrosion current density is higher than $0.1 \mu \mathrm{A} /$ $\mathrm{cm} 2$ and becomes higher than $1 \mu \mathrm{A} / \mathrm{cm} 2$ for free chloride contents around 1.5 to $2 \%$ / wt cement. As a result, conventional current density is closer to the value of the corrosion densities given by the RILEM TC 154 EMC committee (Table 1), which considers that the localized corrosion current density could be represented by the uniform corrosion current density, which obviously uses the entire surface of the steel (by summing the anodic and cathodic areas).

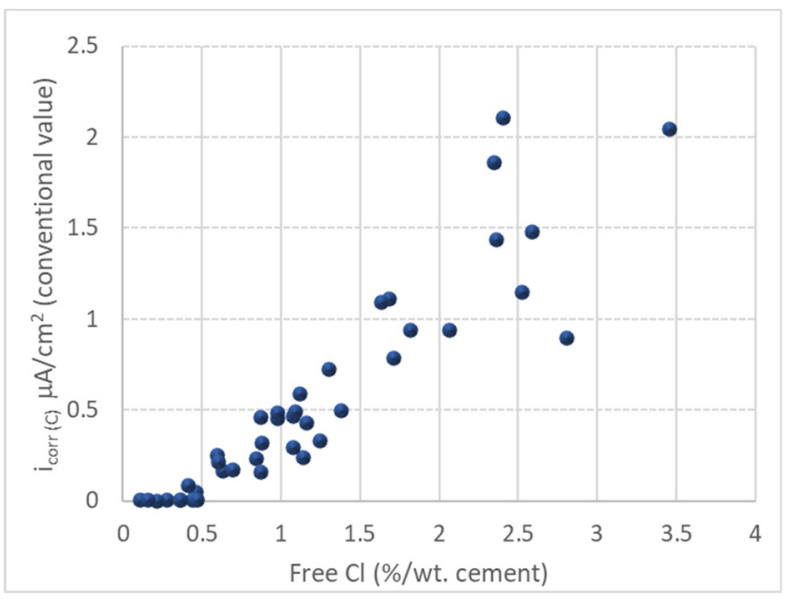

Figure 11. Conventional corrosion current icorr (C) density as a function of the concentration of free chlorides at the anode.

\section{Corrosion current density and resistivity of concrete}

The approach for measuring and calculating the corrosion current density of corrosion presented in this article leads intuitively and necessarily to a strong relationship between corrosion current density and resistivity of the concrete acting as electrolyte.

In the literature $[6,50]$, we also find relationships between corrosion current density and resistivity. Nevertheless, these corrosion current densities always refer to an arbitrary density calculated according to the total surface area of steel, the meaning of which depends on the geometry of the test samples used.

In the case of corrosion by chlorides, given the intrinsically localized nature of corrosion, it is logical that the response to a polarization, via the LPR method, which gives an "apparent" polarization resistance, should be influenced by the resistivity, which governs the exchange of current between anodic and cathodic areas. However, interpretation using the uniform corrosion hypothesis (Stern-Geary) does not provide a reliable relationship between corrosion current density and resistivity.

In a "localized" corrosion process, where the anode and the cathode are spatially separated, there cannot be a single resistivity in the system. In the case of contamination by chlorides, the anode zone shows a much lower resistivity than the cathode zone, due to the ionic movements favored by the presence of chlorides and the degree of saturation, which is also modified. Given the reserve of cathodic surface provided by the stirrups connecting several always passive 
reinforcement layers, one of the important parameters is the influence of the resistivity at the cathode.

Thus in the case of corrosion by chlorides and the measurements carried out by Chalhoub et al. [51], Figure 13 shows a difference of 6.5 between the corrosion current measured between an apparent anode and two different cathodes of different resistivities, which corresponds to the difference in electrical resistance between the two cathodes used at the time the test was carried out: $113 \Omega . \mathrm{m}$ and 737 $\Omega . m$ for the cathodes M1-055 and M10SF-043 respectively.

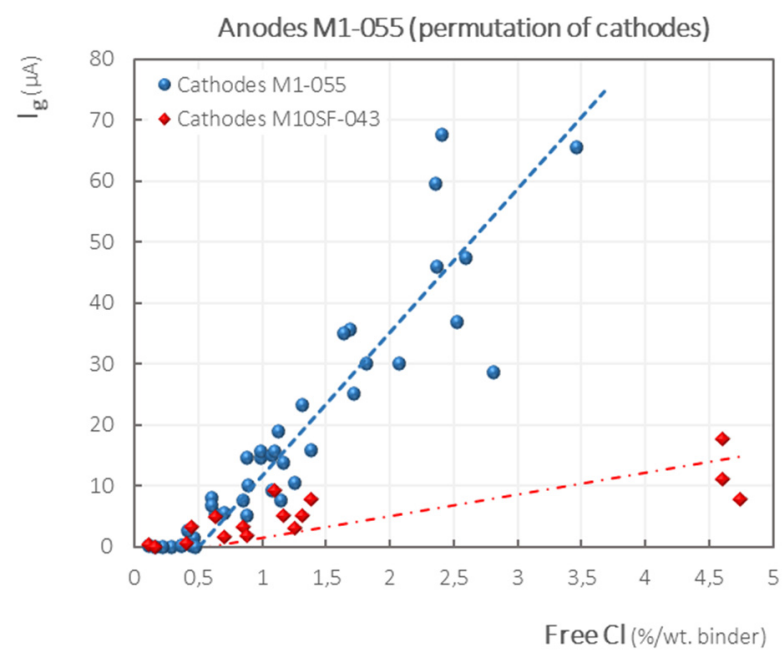

Figure 12. Influence of the resistivity at the cathode on the "galvanic" corrosion current.

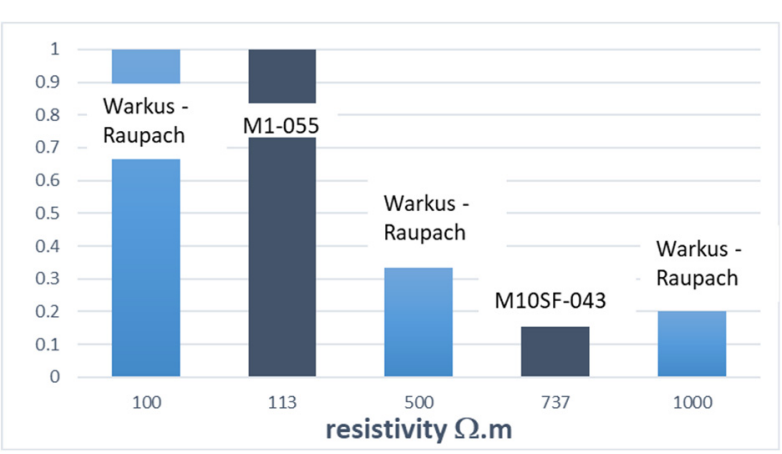

Figure 13. Effect of resistivity on corrosion current density (expressed as a ratio of the value for $100 \Omega$.m concrete).

Warkus and Raupach [14] have measured macrocell corrosion currents between anodes and cathodes for different resistivities, and they found results (Figure 14) which are consistent with those found in this paper. In Figure 14, the macro-cell corrosion currents are normalized and plotted as a ratio of the value for a resistivity reference of $100 \Omega$.m. Hornbostel et al. [52] did not find such direct correlation, which was explained by the fact that diffusion of chloride ions and the availability of water and oxygen are also involved in the macro-cell corrosion process.

The effect of the resistivity on the corrosion current density is not only linked to the ohmic effect (Ohm's law): there is also an important effect of the quantity of cathode surface that can be mobilized in the process of "localized" corrosion, which depends on the resistivity [53]. This point is also support by Angst et al. [54] when corrosion process is established. In 1D approach, the quantity of cathode surface mobilizable could be represented by a maximal distance $\left(C_{m o b}\right)$ where a significant cathodic reaction occurs. This significant cathodic reaction could be defined as value higher than $10 \%$ of the one occurring closed to the anodic site as proposed in [51]. Figure 14 summarizes this concept of zone of influence, making it very clear that the cathodic surface that can be mobilized to exchange with an anodic area decreases very quickly with resistivity $[51,53]$.

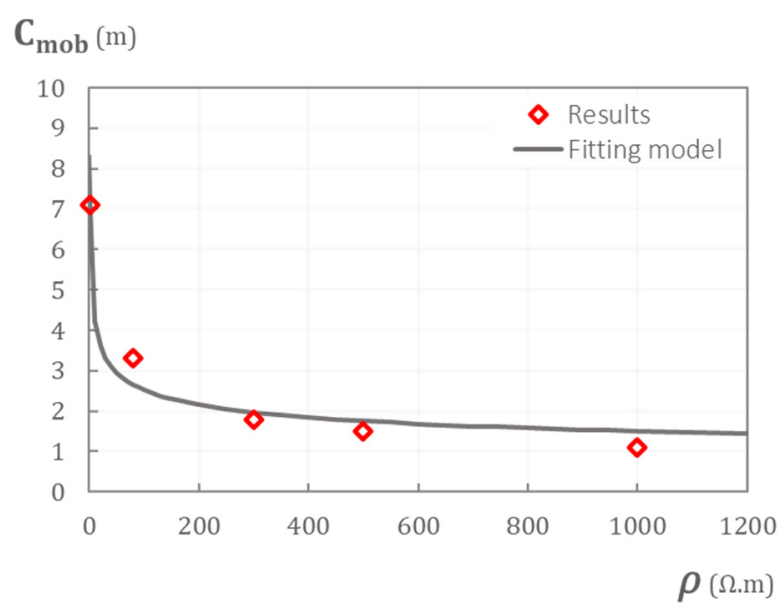

Figure 14. Influence of resistivity on the cathodic length (Cmob parameter (m)) that can be mobilized in a "localized" corrosion process [51].

This phenomenon, well-known in cathodic protection and, in particular, for buried pipelines [55,56], is a major parameter allowing a reduction in the densities of real anodic corrosion in civil engineering structures using concretes more resistive than those based on CEM I.

\section{Corrosion current density and structural consequences}

Proper evaluation of corrosion current density is a key factor for the application of models related to the propagation of corrosion. The propagation phase of corrosion needs to be separated, a minima, in 2 stages: a first step of corrosion process before the appearance of corrosion-induced cracks and a second step of corrosion process after the appearance of corrosion-induced cracks. The duration of the propagation phase must be associated with a level of corrosion related to a pre-defined limit state corresponding to structural or durability performance. This limit state could not be the same in the two stages of the propagation phase. The appearance of the first corrosion-induced cracks is very relevant since it corresponds to the end of the first stage of the propagation phase and is already a criterion which is used in the work of the FIB - AG4 -TG8-9 - WP2 [57].

According to author experience, the first stage of propagation phase corresponds to a localized process where small anodes spots exchange current with large cathodes areas. In this case, electrochemical model such as those propose in [58] or in [42] show that the local corrosion current density is higher at the interface between the anodic spot and the cathode area and then decrease along the anodic area. As a result, the lateral 
expansion is favored and is more important than the in-depth penetration [42]. This effect is influenced by the resistivity of the concrete and is then more pronounced in the case of concrete close to the saturation. In the large cathodic area, significant amounts of $\mathrm{OH}^{-}$(hydroxide) ions are generated and attracted to the adjacent anodic zone by the macrocell electric field, thus impeding large $\mathrm{pH}$ decrease which avoid the acidification of the anodic spot. After the appearance of corrosion-induced cracks, the corrosion process is modified in anodic area since the exchange between anodic spot and cathodic areas is reduced due to the presence of discontinuity in concrete. The $\mathrm{pH}$ is then likely to be reduced in anodic spot leading to a local acidification which increases the in-depth penetration instead of lateral expansion of anodic area. As a result, deep pits appear and are dangerous for the safety of structures due to a more brittle behavior of steel bar. Here also, wetting period are more likely to favor this process.

To avoid this brittle behavior of concrete structures, it is then suitable to use the end of the first stage of propagation phase as a limit state of the service life of concrete structures.

Several models [57,60-64] were developed to predict the time to reach the appearance of the first corrosion-induced crack based on the corrosion current density $\left(i_{\text {corr }}\right)$. As a result, nowadays, there is a trend for current densities to be used by structural engineers to calculate losses of steel cross-section in order to predict the lifetime of structures [65]. However, according to the problem of the unknown anodic area, corrosion current densities are relative to an average between anodic and cathodic areas. A conversion in a reduction of re-bar cross-section is then questionable.

Long term observations of localized corrosion pattern of reinforcement bars, in the first stage of propagation phase, show that the extension of the anodic area on the length of the rebars (lateral extension $\Delta \mathrm{L}_{\mathrm{a}}$ ) (Figure 15) is generally more marked than the cross-section steel loss (the extension indepth $\Delta e_{p}$ ) (Figure 15) [3]. Indeed, the corrosion current densities are higher at the boundary of the anodic site resulting in a higher galvanic coupling at the surface than at depth [42]. Hence, it can be assumed that the corrosion current contributes not only to cross section steel loss (extension in-depth), but also to the extension of the anodic area on the length of the rebars (lateral extension).

A possible approach to solve the problem of relationship between corrosion current density and loss of cross-section, is to separate the corrosion current density in two parts : one which contributes to the lateral extension of the anodic site and one corresponding to in-depth penetration [66]. Pit growth rate in a rebar in concrete was already mentioned to be a 3D phenomenon by Polder et al. [58] : their approach was very promising but at this time did not go further than a conceptual approach. Garcia [42] proposes also an electrochemical approach allowing to show that the most significant part of the corrosion current leads to increase the surface of the anodic spot while only a small part of the corrosion current leads to in-depth penetration.

Figure 15 proposed a geometry of the corrosion pit based on the one presented in [3], where, at a given propagation time $t_{\text {prop}}, e_{p}$ is the pit depth, $L_{a}$ the pit length, $A_{a}$ the anodic surface of the pit. $D$ is the diameter of the re-bar and $\varphi$ is the penetration angle of the pit. $\Delta \mathrm{L}_{\mathrm{a}}$ and $\Delta \mathrm{e}_{\mathrm{p}}$ represent the extents of the pit at $\Delta t+t_{\text {prop. }}$. From this geometry, it is possible to determine the relationship between the corrosion current density and the mass loss of the steel bar.

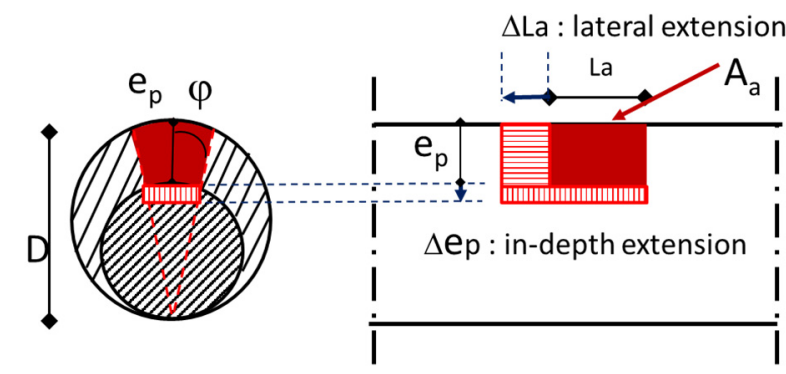

Figure 15. Localized corrosion of reinforcement rebar : in-depth and lateral extension of anodic site.

At a given time $t_{p r o p}$, the area of the anodic zone is given in Eq. 2 and the volume of the anodic zone can be calculated with Eq. 3. The loss of mass due to corrosion is then calculated using Faraday law (Eq. 4) using only a part of the corrosion current $I_{\text {corre }}$ which contribute to the in-depth corrosion. The corrosion current is then share in two parts : $I_{\text {corre }}$ for in depth penetration of anodic area and $I_{\text {corr }}$ for lateral extension of anodic area. The corrosion current $I_{\text {coore }}$ and $I_{\text {coorl }}$ are linked to the corrosion current density $i_{\text {corr }}$ using the anodic surface $A_{a}$ as shown in Eq. 5 and Eq. 6 .

$$
\begin{aligned}
& \mathrm{A}_{\mathrm{a}}=2 \mathrm{~L}_{\mathrm{a}} \mathrm{D} \tan (\varphi) \\
& \mathrm{V}_{\mathrm{a}}=\mathrm{A}_{\mathrm{a}} \mathrm{e}_{\mathrm{p}} \\
& \mathrm{m}=\mathrm{V}_{\mathrm{a}} \mathrm{\rho}_{\mathrm{s}}=\frac{M I_{\text {corre }} t_{\text {prop }}}{z F} \\
& \mathrm{I}_{\text {corre }}=K_{c} \mathrm{I}_{\text {corr }}=K_{c} \mathrm{i}_{\text {corr }} \mathrm{A}_{\mathrm{a}} \\
& \mathrm{I}_{\text {corrL }}=\left(1-K_{c}\right) \mathrm{I}_{\text {corr }}=\left(1-K_{c}\right) \mathrm{i}_{\text {corr }} \mathrm{A}_{\mathrm{a}}
\end{aligned}
$$

where:

- $A_{a}$ is the surface of the lateral extension of the active anodic area $\left(\mathrm{m}^{2}\right)$;

- $\mathrm{L}_{\mathrm{a}}$ is the length of the active anodic area $(\mathrm{m})$;

- $\varphi$ is half of the opening angle of the triangle that is considered equal to $\frac{\pi}{12}$ (according to [3]);

- $\quad V_{a}$ is the volume of the anodic zone $\left(\mathrm{m}^{3}\right)$;

- $t_{\text {prop }}$ is the corrosion propagation duration (s);

- $\mathrm{M}$ is the molar mass of iron;

- $\mathrm{i}_{\text {corre }}$ is the corrosion current density contributing to the in-depth extension of the anodic area;

- $K_{c}$ is the factor corresponding to the part of corrosion current leading to steel cross-section loss which need further research to be characterized;

- $\quad \mathrm{i}_{\text {corr }}$ is the corrosion current density based on the real anodic surface.

As a result of this approach, only a part of the corrosion current density will be used to calculate the cross-section mass loss.

The on-site evaluation of the corrosion current density could then be correlated to the loss-of cross-section by using the 
Eq. 5, which allow to separate the in-depth and lateral expansion of anodic areas. As a result, this is a clear relationship between corrosion and mechanics useful for structural engineers.

Others approaches have been done to link the pitting depth to the chloride-induced corrosion activity (namely $I_{\text {corr }}$ the corrosion current or $\mathrm{i}_{\text {corr }}$ the corrosion current density by considering the anodic area $A_{a}$ ). A pitting factor $\alpha_{\text {pit }}$ was introduced by Gonzales et al. [16] and Ullig et al. [67], but the applicability of the factor is questionable as it is poorly related to the residual steel cross-section as quoted by Harnisch and Raupach [25]. Val and Melchers [68] try to give a less conservative calculation of the residual cross-section based on the pitting depth, using a dome shaped corrosion pit. Harnisch and Raupach [25] introduced a residual cross section factor $\alpha A_{s}(t)$ which is time dependent and represent the ratio between the corrosion depth calculated from the minimum residual cross-section and the general corrosion depth calculated from $I_{\text {corr. }}$.

The pitting factor is a non-time dependent geometrical factor between average corrosion loss in a cross-section and maximal pit depth. The residual cross-section factor is based on the examination of the residual cross-section of corroding steel, it needs extensive laboratory tests and examination of existing structure. Nevertheless, both factors are twodimensional, while pitting is clearly a 3D phenomenon [58]]. Therefore, pitting factor or residual cross-section factor are totally different of the ratio between in-depth penetration and lateral extension $\left(K_{c}\right)$ defined in this paper which could be modelled and predicted using electrochemical mechanisms.

\section{Conclusion}

In the view of service life evaluation of corroding concrete structures, it is important to consider that the propagation period of corrosion encompasses two stages: before and after corrosion-induced cracking. The concluding remarks of the paper concerns only the first stage of the propagation period, and the limit state of service life of concrete structures is then defined as the appearance of the first corrosion-induced crack.

It is then necessary to be able to measure and predict the actual corrosion current density in corroding structure in the first stage of propagation, considering the phenomenon of localized corrosion induced by chlorides. An example of physically realistic measurement protocol, suitable for laboratory measurement, is the one developed by Chalhoub et al. [39]. From this protocol, it appears that the corrosion current density could be in the order of $50-200 \mu \mathrm{A} / \mathrm{cm}^{2}$ before the appearance of the corrosion-induced cracks. These values correspond to a high saturation degree in concrete and then to the upper values which could be found during the corrosion process.

It is also necessary to completely review the in-situ diagnostic methods for the evaluation of anodic corrosion densities. These methods must imperatively be able to evaluate the real geometries and surfaces of the anodic zones in order to allow a realistic calculation of the corrosion current densities.
A new approach was recently proposed by Angst and Büchler [69] based on galvanostatic pulse measurements and the analysis of the polarization behavior of the anodic part of the macrocell. Nevertheless, the size of the anodic zone is not characterized and so the corrosion current density is still unknown even if the measurement takes the real physical aspect of the corrosion process in reinforced concrete structures into account.

In localized corrosion process, the cathode areas close to the anode spots have stronger activity, which decreases as the distance from the anode area increases $[51,53]$. The increase in electrical resistivity reduces the cathode-anode distance allowing a significant current flow (mobilizable C-A distance). Therefore, a higher resistivity would restrain the corrosion current density in anodic areas. As a result, binders using silica fume or slag would be beneficial to reduce corrosion activity induced by chlorides.

Although the measurement of the current corrosion densities is correct, there is still a need to characterize which fraction of this corrosion current is used to reduce the cross-section and which fraction is used in lateral expansion of the anodic area. An approach was proposed by Chalhoub et al. [66] where the corrosion current leading to a reduction of cross-section is only a part of the total corrosion current through a coefficient $\mathrm{K}_{c}$ (Eq. 5). Further research is needed to characterize this parameter factor $\mathrm{K}_{\mathrm{c}}$. Numerical modelling using electrochemical mechanisms as conceptualized by Polder et al. [58] and tentatively drafted by Garcia [42] is a promising approach to characterize the ratio between lateral extension and in-depth penetration in anodic area (factor $\mathrm{K}_{\mathrm{c}}$ ). From the actual corrosion current density in anodic area, the determination of $\mathrm{K}_{\mathrm{c}}$ would allow to determine the part of corrosion current density leading to in-depth penetration and then the load-bearing capacity. The characterization of both lateral expansion and in-depth penetration of anodic area would allow to predict the time for the appearance of corrosion-induced cracks corresponding to a limit state of reinforced concrete service life.

\section{List of symbols}

Icorr corrosion density in case of localized corrosion in RILEM TC-154$\operatorname{EMC}\left(\mathrm{A} / \mathrm{cm}^{2}\right)$;

I pit corrosion density at the pitting site in RILEM TC-154-EMC $\left(\mathrm{A} / \mathrm{cm}^{2}\right)$;

Ig Galvanic (macrocell) corrosion current between apparent anode and cathode in Chalhoub et al. experiment (A);

$i_{\text {corr }}$ corrosion current density equal to the Galvanic current (macrocell) divided by the actual anodic surface $\left(A / \mathrm{cm}^{2}\right)$;

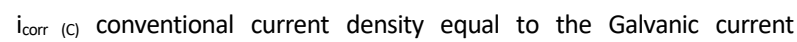
(macrocell) divided by the total surface of the steel (sum of anodic zones and cathodic zones) $\left(\mathrm{A} / \mathrm{cm}^{2}\right)$;

Icorre corrosion current contributing to in-depth corrosion $(A)$;

icorre corrosion current density contributing to in-depth corrosion $\left(\mathrm{A} / \mathrm{cm}^{2}\right)$;

$\mathrm{K}_{\mathrm{c}}$ factor corresponding to the part of corrosion current density leading to cross-section loss;

m metal loss (g);

M molar mass of steel equal to $55.8 \mathrm{~g} / \mathrm{mol}$;

$t_{\text {prop }} \quad$ corrosion propagation duration (s); 
Z metal valence equal to 2;

F Faraday constant equal to 96500 A.s/mol;

$\mathrm{C}_{\text {mob }} \quad$ mobilizable cathodic length in a macrocell process $(\mathrm{m})$;

$A_{a} \quad$ is the surface of the lateral extension of the active anodic area $\left(\mathrm{m}^{2}\right)$;

$\mathrm{L}_{\mathrm{a}} \quad$ is the length of the active anodic area $(\mathrm{m})$;

$\varphi \quad$ is half of the opening angle of the triangle that is considered equal to $\frac{\pi}{12}$ (according to [3]);

$V_{a} \quad$ is the volume of the anodic zone $\left(\mathrm{m}^{3}\right)$;

$t_{\text {prop }} \quad$ is the corrosion propagation duration (s);

$\alpha_{\text {pit }} \quad$ pitting factor;

$\alpha A_{s}(t) \quad$ residual cross-section factor.

\section{Authorship statement (CRediT)}

\section{Raoul François : Conceptualization, Writing - original draft.}

\section{References}

[1] U. Angst, Challenges and opportunities in corrosion of steel in concrete, Mater Struct (2018) 51:4. https://doi.org/10.1617/s11527-017-1131-6

[2] RILEM TC-154-EMC, Recommendations of RILEM TC-154-EMC: "Electrochemical techniques for measuring metallic corrosion" Test methods for on-site corrosion rate measurement of steel reinforcement in concrete by means of the polarization resistance method, Mater Struct (2004) 37: 623-643. https://doi.org/10.1617/13952

[3] R. Francois, S. Laurens, F. Deby, Corrosion and Its Consequences for Reinforced Concrete Structures, Elsevier, 2018. https://doi.org/10.1016/B978-1-78548-234-2.50001-9

[4] L. Bertolini, B. Elsener, P. Pedeferri, R. Polder, Corrosion of steel in concrete : prevention, diagnosis, repair, Wiley, Weinheim, Germany, 2004. https://doi.org/10.1002/3527603379

[5] J. P. Broomfield, J. Rodriguez, L. M. Ortega, A. M. Garcia, in: Concrete Bridges in Aggressive Environments, Philip D. Cady International Symposium, Minneapolis, November 9-10, 1993, Weyers, R.E.(Ed.)), Detroit, American Concrete Institute, ACI SP-151, 1994. P. 163-181.

[6] B. Elsener, Macrocell Corrosion of Steel in Concrete - Implications for Corrosion Monitoring, Vol. 24, 2002. https://doi.org/10.1016/S0958-9465(01)00027-0

[7] T. Liu, R.W. Weyers, Modeling the Dynamic Corrosion Process in Chloride Contaminated Concrete Structures, Vol. 28, 1998. https://doi.org/10.1016/S0008-8846(98)00259-2

[8] A.N. Scott, The Influence of Binder Type and Cracking on Reinforcing Steel Corrosion in Concrete, 2004.

[9] J. Warkus, M. Raupach, Modelling of reinforcement corrosion Corrosion with extensive cathodes, Mater Corros (2006) 57(12). https://doi.org/10.1002/maco.200604032

[10] C. Andrade, Propagation of reinforcement corrosion: principles, testing and modelling, Mater Struct (2019) 52: 2. https://doi.org/10.1617/s11527-018-1301-1

[11] G. Di Pace, R. Torrent, a heuristic model for corrosion propagation time, Mathematical models on reinforcement corrosion and its consequences for structural performance, IFSTTAR, France, 2019

[12] Y. Wang, C. Liu, Y. Wang, Q. Li, B. Yan, Semi-empirical model of chloride-induced corrosion rate in uncracked reinforced concrete exposed to marine environment, Electrochimica Acta (2020) 135376. https://doi.org/10.1016/j.electacta.2019.135376

[13] A.A. Sagües, M.A. Pech-Canul, A.K.M. Shahid Al-Mansur, Corrosion macrocell behavior of reinforcing steel in partially submerged concrete columns, Corros Sci (2003) 45: 7-32 https://doi.org/10.1016/S0010-938X(02)00087-2

[14] J. Warkus, M. Raupach, Modelling of reinforcement corrosion geometrical effects on macrocell corrosion, Mater Corros (2010) 64: 494-504. https://doi.org/10.1002/maco.200905437

[15] S. Jäggi, H. Böhni, B. Elsener, Macrocell corrosion of steel in concrete - experiments and numerical modelling, Euroccor 2001, Riva di Garda, Italy, 2001.

[16] J.A. González, C. Andrade, C. Alonso, S. Feliu, Comparison of rates of general corrosion and maximum pitting penetration on concrete embedded steel reinforcement, Cem Concr Res (1995) 25: 257-264. https://doi.org/10.1016/0008-8846(95)00006-2
[17] C. Andrade, C. Alonso, On-site measurement of corrosion rate of reinforcements, Constr Build Mater (2001) 15: 141-145. https://doi.org/10.1016/S0950-0618(00)00063-5

[18] B. Elsener, Corrosion rate of steel in concrete - Measurements beyond the Tafel law, Corros Sci (2005) 47: 3019-3033. https://doi.org/10.1016/j.corsci.2005.06.021

[19] F. Bolzoni, A. Brenna, M. Ormellese, MP. Pedeferri, Corrosion propagation: comparison of electrochemical and mass loss measurements, FIB Workshop : Mathematical models on reinforcement corrosion and its consequences for structural performance, IFSTTAR, France, 2019.

[20] K. Tuutti, Corrosion of steel in concrete, Swedish Cement and Concrete Research Institute, 1982.

[21] J.A. González, C. Andrade, C. Alonso, S. Feliu, Comparison of rates of general corrosion and maximum pitting penetration on concrete embedded steel reinforcement, Cem Concr Res (1995) 25: 257-264. https://doi.org/10.1016/0008-8846(95)00006-2

[22] J. Rodriguez, L. Ortega, J. Casal, Load carrying capacity of concrete structures with corroded reinforcement, Constr Build Mater (1997) 11: 239-248. https://doi.org/10.1016/S0950-0618(97)00043-3

[23] C.A. Apostolopoulos, S. Demis, V.G. Papadakis, Chloride-induced corrosion of steel reinforcement - Mechanical performance and pit depth analysis, Constr Build Mater (2013) 38: 139-146. https://doi.org/10.1016/j.conbuildmat.2012.07.087

[24] A. Torres-Acosta, M. Martı'nez-Madrid, Residual Life of Corroding Reinforced Concrete Structures in Marine Environment, J Mater Civ Eng (2003) 15: 344-353. https://doi.org/10.1061/(ASCE)0899-1561(2003)15:4(344)

[25] J. Harnisch, M. Raupach, The residual cross section factor as a key parameter for the static evaluation of corroding reinforced concrete structures, Mater Corros (2015) 66: 829. https://doi.org/10.1002/maco.201408066

[26] L. Yu, R. François, V.H. Dang, V. L'Hostis, R. Gagné, Distribution of corrosion and pitting factor of steel in corroded RC beams, Constr Build Mater (2015) 95: 384-392. https://doi.org/10.1016/j.conbuildmat.2015.07.119

[27] M. Stern, A.L. Geary, Electrochemical Polarization I. A Theoretical Analysis of the Shape of Polarization Curves (1957) 104. https://doi.org/10.1149/1.2428473

[28] C. Alonso, C. Andrade, J.A. González, Relation between Resistivity and Corrosion Rate of Reinforcement in Carbonated Mortar Made with Several Cement Types, Cem Concr Res (1988) 18: 687-698. https://doi.org/10.1016/0008-8846(88)90091-9

[29] U. Angst, M. Büchler, On the applicability of the Stern-Geary relationship to determine instantaneous corrosion rates in macro-cell corrosion, Mater Corros (2014) 66: 1017-1028. https://doi.org/10.1002/maco.201407997

[30] A. Clément, S. Laurens, G. Arliguie, F. Deby, Numerical Study of the Linear Polarisation Resistance Technique Applied to Reinforced Concrete for Corrosion Assessment, European J Env Civ Eng (2012) 16. https://doi.org/10.1080/19648189.2012.668012

[31] J. Marchand, S. Laurens, Y. Protière, E. Samson, A Numerical Study of Polarization Tests Applied to Corrosion in Reinforced Concrete, $\mathrm{ACl}$ Special Publication, SP 312 - 02, 2016.

[32] B. Elsener, Macrocell Corrosion of Steel in Concrete - Implications for Corrosion Monitoring, Cem Concr Compos (2002) 24: 65-72. https://doi.org/10.1016/S0958-9465(01)00027-0

[33] S. Laurens, Corrosion de l'acier dans le béton armé et mesures associées. Modélisation, simulation numérique et expérimentation. Rapport d'activités scientifiques Congé pour Recherche 2011-2012, LMDC - INSA, 2012

[34] C. Andrade, I. Martinez, Calibration by gravimetric losses of electrochemical corrosion rate measurement using modulated confinement of the current. Mater Struct (2005) 38: 833-841 https://doi.org/10.1007/BF02481656

[35] J.A. Gonzalez, C. Andrade, C. Alonso, S. Feliu', Comparison of rates of general corrosion and maximum pitting penetration of concrete embedded steel reinforcement. Cem Concr Res (1995) 25(2): 257264. https://doi.org/10.1016/0008-8846(95)00006-2

[36] D.W. Law, J. Cairns, S.G. Millard, J.H. Bungey, Measurement of loss of steel from reinforcing bars in concrete using linear polarisation resistance measurements, NDT \& E International (2004) 37(5):381388. https://doi.org/10.1016/j.ndteint.2003.11.003

[37] J. Shi, W. Sun, J. Ming, Characterization of corrosion behaviors of steel in concrete by time and frequency domain electrochemical methods. Procedia Eng (2012) 27: 412-422. https://doi.org/10.1016/j.proeng.2011.12.469 
[38] S.A. Alghamdi, S. Ahmad, Service life prediction of RC structures based on correlation between electrochemical and gravimetric reinforcement corrosion rates, Cem Concr Compos (2014) 47: 64-68. https://doi.org/10.1016/j.cemconcomp.2013.06.003

[39] C. Chalhoub, R. François, M. Carcasses, Determination of chloride threshold initiating corrosion: A new set-up taking the localized aspect of corrosion into account, Cem Concr Res (2019) 124: 105825. https://doi.org/10.1016/j.cemconres.2019.105825

[40] C. Andrade, I. Maribona, S. Feliu, J. González, S. Feliu Jr, The Effect of Macrocells between Active and Passive Areas of Steel Reinforcements, Corros Sci (1992) 33(2): 237-249. https://doi.org/10.1016/0010-938X(92)90148-V

[41] K.V. Subramaniam, M. Bi, Investigation of steel corrosion in cracked concrete: evaluation of microcell and microcell rates using Tafel polarization response, Corros Sci (2010) 52: 2725-2735. https://doi.org/10.1016/j.corsci.2010.04.030

[42] D. Garcia, PhD Thesis, Université de Toulouse, 2020

[43] J.P. Darr, S.Q. Davis, Y. Kohno, K. McKenna, P. Morales, Morphological effects of the hygroscopic properties of sodium chloride-sodium sulfate aerosols, J Aerosol Sci (2014) 77: 158-167. https://doi.org/10.1016/i.jaerosci.2014.08.002

[44] L. Hess, study of the corrosion mechanism at the crack tip of reinforced concrete in the presence of chlorides, (in French), MSc Thesis, University of Toulouse, 2020.

[45] C. Chalhoub, R. François and M. Carcasses, Critical chloride threshold values as a function of cement type and steel surface condition, Cem Concr Res (2020) 134: 106086. https://doi.org/10.1016/j.cemconres.2020.106086

[46] S. Robuschi, A. Tengattini, J. Dijkstra, I. Fernandez, A closer look at corrosion of steel reinforcement bars in concrete using 3D neutron and X-ray computed tomography, Cem Concr Res (2021) 144: 106439. https://doi.org/10.1016/j.cemconres.2021.106439

[47] S. Jäggi, H. Böhni, B. Elsener, Macrocell corrosion of steel in concrete - Experiments and numerical modelling, European Federation of Corrosion (2001)

[48] H. Yalçyn, M. Ergun, The prediction of corrosion rates of reinforcing steels in concrete, Cem Concr Res (1996) 26: 1593-1599. https://doi.org/10.1016/0008-8846(96)00139-1

[49] M. Ormellese, M. Berra, F. Bolzoni, T. Pastore, Corrosion inhibitors for chlorides induced corrosion in reinforced concrete structures, Cem Concr Res (2006) 36: 536-547. https://doi.org/10.1016/i.cemconres.2005.11.007

[50] RILEM TC 154-EMC: Electrochemical techniques for measuring metallic corrosion. Test methods for on site measurement of resistivity of concrete, Mater Struct, (2000) 33: 603-611.

[51] C. Chalhoub, R. François, M. Carcasses, Effect of Cathode-Anode distance and electrical resistivity on macrocell corrosion currents and cathodic response in cases of chloride induced corrosion in reinforced concrete structures, Constr Build Mater (2020) 245: 118337. https://doi.org/10.1016/i.conbuildmat.2020.118337

[52] K. Hornbostel, U.M. Angst, B. Elsener, C.K. Larsen, M.R. Geiker, On the limitations of predicting the ohmic resistance in a macro-cell in mortar from bulk resistivity measurements, Cem Concr Res (2015) 76: 147-158. https://doi.org/10.1016/i.cemconres.2015.05.023

[53] A. Arya, P.R.W. Vassie, Influence of Cathode-to-Anode Area Ratio and Separation Distance on Galvanic Corrosion Currents of Steel in Concrete Containing Chlorides, Cem Concr Res (1995) 25: 989-998. https://doi.org/10.1016/0008-8846(95)00094-S

[54] U. Angst, B. Elsener, C.K. Larsen, $\varnothing$.Vennesland, Chloride induced reinforcement corrosion: Rate limiting step of early pitting corrosion, Electrochimica Acta (2011) 56: 5877-5889 https://doi.org/10.1016/j.electacta.2011.04.124

[55] P. Pedeferri, Macrocell Corrosion Mechanism. In Corrosion Science and Engineering; P. Pedeferri (Ed.), Springer Int Publishing: Cham, 2018, 169-182. https://doi.org/10.1007/978-3-319-97625-9 9

[56] I. Lazzari, Engineering Tools for Corrosion: Design and Diagnosis; Woodhead Publishing, 2017. https://doi.org/10.1016/B978-0-08-102424-9.00002-1

[57] F. Papworth, S. Matthews, fib Model Code 2020 - Durability Design and Through Life Management of New and Existing Structures, Sixth International Conference on Durability of Concrete Structures, 2018, University of Leeds, UK.

[58] R.B. Polder, U.M. Angst, J. Pacheco, W.H.A. Peelen, Propagation of pitting corrosion of steel in concrete: conceptual models for local cross section loss, 6th International Conference on Concrete Repair, Thessaloniki, Greece, CRC Press, 2016, 417-421.
[59] C. Andrade, C. Alonso, F. Molina, Cover Cracking as a Function of Bar Corrosion: Part I-Experimental Test, Mater Struct (1993) 26: 453-464. https://doi.org/10.1007/BF02472805

[60] T. El Maaddawy, K. Soudki, A Model for Prediction of Time from Corrosion Initiation to Corrosion Cracking, Cem Concr Compos (2007) 29: 168-175. https://doi.org/10.1016/j.cemconcomp.2006.11.004

[61] J.A. Mullard, M.G. Stewart, Corrosion-Induced Cover Cracking: New Test Data and Predictive Models, Struct J (2011) 108 https://doi.org/10.14359/51664204

[62] Y. Liu, Modeling the Time-to-Corrosion Cracking of the Cover Concrete in Chloride Contaminated Reinforced Concrete Structures, PhD Thesis, Faculty of the Virginia Polytechnic Institute, 1996.

[63] K. Vu, M. Stewart, J. Mullard, Corrosion-induced cracking: Experimental data and predictive models, ACl Struct J (2005) 102: 719-726. https://doi.org/10.14359/14667

[64] C.Q. Li, R.E. Melchers and J. Zheng, Analytical Model for CorrosionInduced Crack Width in Reinforced Concrete Structures, ACl Struct J (2006) 103: 479-487. https://doi.org/10.14359/16423

[65] C. Andrade, corrosion rates and modelling, FIB Workshop: Mathematical models on reinforcement corrosion and its consequences for structural performance, IFSTTAR, France, 2019.

[66] C. Chalhoub, R. François, M. Carcasses, Prediction of corrosion current density during the propagation phase of corrosion and its duration before the appearance of first corrosion-induced cracks as a function of environmental conditions, IFSTTAR, France, 2019.

[67] H.H Uhlig, R.W. Revie, Corrosion and corrosion control: an introduction to corrosion science and engineering. Third edition, Wiley, New York, 1985.

[68] D. Val, R.E Melchers, Reliability analysis of deteriorating reinforced concrete frame structures. Structural safety and reliability, Balkema, Rotterdam 1998, 105-112.

[69] U. Angst, M. Büchler, A new perspective on measuring the corrosion rate of localized corrosion, Mater Corros (2020) 71: 808-823. https://doi.org/10.1002/maco.201911467 